\title{
Review Article \\ Regulation of the Induction and Function of Cytotoxic $T$ Lymphocytes by Natural Killer T Cell
}

\author{
Hiroyasu Ito and Mitsuru Seishima \\ Department of Informative Clinical Medicine, Gifu University Graduate School of Medicine, 1-1 Yanagido, Gifu City 501-1194, Japan \\ Correspondence should be addressed to Hiroyasu Ito, hito@gifu-u.ac.jp
}

Received 29 November 2009; Revised 14 February 2010; Accepted 9 March 2010

Academic Editor: Kim Klonowski

Copyright ( $) 2010 \mathrm{H}$. Ito and M. Seishima. This is an open access article distributed under the Creative Commons Attribution License, which permits unrestricted use, distribution, and reproduction in any medium, provided the original work is properly cited.

Cytotoxic T lymphocytes (CTLs) play a crucial role in the infections and the antitumor immunity. Induction and activation of antigen-specific CTLs is an important strategy in immunotherapy for various diseases, and several researchers have focused on the modulation of CTL induction and function. Natural killer T (NKT) cells are an important focus area of researchers studying immunomodulatory responses to tumors and infectious diseases. CD1d-restricted NKT cells consist of type I NKT cells and type II NKT cells. $\alpha$-galactosylceramide ( $\alpha$-GalCer)-activated type I NKT cells secrete both Th1 (e.g., IFN- $\gamma$ ) and Th2 cytokines, affect the expression of costimulatory molecules in immune cells, and regulate the host immune system. Type II NKT cells, however, are stimulated by sulfatide, a self-glycolipid derived from myelin, and play an immunosuppressive role in animal model of autoimmune diseases. CTL generation, activation, and suppression are strongly affected by activated type I and type II NKT cells. Thus, the regulation of these NKT cells leads to the modification of CTL function. CTLs contribute to antimicrobial responses, antitumor immune and autoimmune responses. Understanding the role of NKT cells in the regulation of CTL generation, activation, and suppression enable the development of novel treatment strategies for these diseases.

\section{Introduction}

Cytotoxic T lymphocytes (CTLs) constitute a distinct lymphocyte subpopulation, and are induced by several diverse stimuli, including major histocompatibility antigens, protein antigens, viruses, and intracellular bacteria and parasites. CTLs recognize peptides bound to the major histocompatibility complex (MHC) class I molecules, and the activation and proliferation of CTLs are induced by exposure to specific antigens. Activated CTLs secrete the essential cytolytic mediators (perforin, granzyme, etc.) and induce apoptosis in target cells (tumor cells, viral infected cells, etc.). Moreover, activated CTLs secrete various cytokines such as interferon gamma (IFN- $\gamma$ ) and tumor necrosis factor alpha (TNF- $\alpha$ ), which enhance antigen presentation and mediate antipathogenic effects. Previous reports showed that various cytokines such as interleukin-(IL2) or IFN$\gamma$-producing CD4 $\mathrm{T}$-cells are required for the generation of effective CTL immunity to infection and cancer $[1,2]$. The modulation of CTLs induction and functions is critical for designing effective strategies against various viruses and tumors.

CD1d-restricted natural killer $\mathrm{T}$ (NKT) cells have recently gained importance as one of the regulators of the immune system. NKT cells play a role in immune responses in infections, cancers, allergies, autoimmune disease, and so forth. NKT cells form a unique lymphocyte population that expresses both natural killer (NK) receptors and T cell receptors (TCRs). Most NKT cells utilize an invariant TCR- $\alpha$ chain rearrangement $(\mathrm{V} \alpha 14-\mathrm{J} \alpha 18$ in mice and $\mathrm{V} \alpha 24-\mathrm{J} \alpha 18$ in humans). Studies on NKT cell have mostly been performed using $\alpha$-galactosylceramide ( $\alpha$-GalCer); this compound was isolated from a marine sponge and developed as an antitumor compound and is not found in mammalian cells [3]. Several NKT cells in mice are stained with $\alpha$-GalCer loaded onto the CD1d-tetramer. These $\alpha$-GalCer-reactive NKT cells are called invariant or type I NKT cells. Type I NKT cells have the remarkable ability to produce both Th1 (e.g., IFN- $\gamma$ ) and Th2 (e.g., IL-4, IL-10) cytokines on stimulation and can subsequently help activate other 
immune cells, such as T cells, natural killer (NK) cells, or dendritic cells (DCs) [4]. Activated invariant NKT cells, like other cytotoxic cells such as NK cells or CTLs, can induce cell death in target cells by expressing cell-death-inducing effector molecules, including the Fas ligand (FasL) and the TNF-related apoptosis-inducing ligand (TRAIL) $[5,6]$.

Some CD1d-restricted NKT cells do not express V $\alpha 14-$ $\mathrm{J} \alpha 18$; they are called nonclassical or type II NKT cells. These cells are more heterogeneous than type I NKT cells in terms of both TCR $\alpha$ and TCR $\beta$ chain usage; however, they also produce both Th1 and Th2 cytokines on TCR stimulation [7-9]. Recently, sulfatide, a self-glycolipid derived from myelin, was reported to specifically stimulate type II NKT cells [10]. The injection of sulfatide in vivo strongly prevented disease onset in a model of Th-1-induced experimental autoimmune encephalitis; this suggests that type II NKT cells have a strong immunoregulatory function. Other studies have reported the immunosuppressive role of type II NKT cells $[11,12]$. On the other hand, it was previously reported that type II NKT cells are activated in response to hepatocytes expressing hepatitis $\mathrm{B}$ viral antigens in a transgenic mice model of acute hepatitis B virus infection [7]. In this model, type II NKT cells can cause liver cell injury and recruit lymphomononuclear inflammatory cells. Thus, type II NKT cells may have the ability to induce the inflammatory. NKT cells (type I and type II) play a critical role in immune modulation. In the present paper, we have reviewed the role of NKT cells in the regulation of immunological responses, particularly CTL induction and function.

\section{Role of NKT Cells in CTL Induction and Activation}

Several studies have shown that the activation of type I NKT cells is intimately associated with the elimination of cancer cells [13-15], or various pathogens [16-18]. CTLs are involved in adaptive immune responses and are key players in mediating immunity against pathogens and tumors. The enhancement of CTL induction and activation via type I NKT cell activation causes immunopotentiation against tumors or microbes. In several studies, IL-12 or $\alpha$-GalCer was generally used to activate type I NKT cells $[15,19,20]$. IL-12 administration can large amount of Th-1 cytokine $(\mathrm{IFN}-\gamma)$ in type I NKT cells-dependent manner [21]. On the other hand, activated type I NKT cells by $\alpha$-GalCer secrete both Th-1 (IFN- $\gamma$ ) and Th-2 (IL-4) cytokines. Thus, various stimulatory substances of type I NKT cells exhibit different patterns of cytokines production. Our group has previously evaluated and confirmed the role of activated NKT cells in the induction of hepatitis B virus-(HBV-) specific CTLs [22]. Moreover, HBV-specific CTL precursor cells are frequently observed in the spleens of HBV surface antigen (HBsAg) transgenic mice; these mice show immunological tolerance to the HBsAg when animals are pretreated with $\mathrm{HBsAg}$ and $\alpha$-GalCer. Consistent with this result, enhanced T cell responses were observed using $\mathrm{OCH}$, an analog of alphaGalCer with a truncated sphingosine chain and a reduced capacity to induce IFN- $\gamma$ [23]. This report demonstrated that the enhancing effect of iNKT cell stimulation on T cell responses does not require IFN- $\gamma$. In this section, we summarize the mechanism of CTL induction and activation after the activation of type I NKT cells in response to various stimuli including cytokines, costimulatory molecules, and dendritic cells (DCs). Various cytokines, costimulatory molecules, and DCs strongly contribute to the induction and activation of CTLs (Figure 1).

\subsection{Cytokines Mediate CTL Induction via NKT Cell Acti-} vation. $\mathrm{CD} 8$-positive $\mathrm{T}$ cells require various stimuli to become fully activated and to induce differentiation and proliferation. Several cytokines, costimulatory molecules, and immune cells play critical role in CTL induction and activation. Several recombinant cytokines, namely, IL2 [24], IL-4 [25], IL-7 [26], IL-10 [27], IL-12 [28], IL-15 [29], and TNF- $\alpha$ [30], were found to significantly enhance CTL production. The extent of enhancement depends on the particular antigen, responding cell populations, and various environments. In particular, IL-2 was found to potently induce specific cytotoxicity. IL-2 was found to be an important endogenous cytokine for CTL production because cells from IL-2-deficient mice show impaired CTL production in vitro [31], and treatment with anti-IL-2 [22] or anti-IL-2 receptor [32] antibodies blocks CTL production. Recently, Lin et al. also demonstrated that DNA vaccine encoding a fusion of IL-2 and E7 proteins generated the highest frequency of E7-specific CD8+ T cells in vivo [33]. IL-2 seemed to be a critical cytokine for CTL induction in vivo. We have previously reported that the activation of type I NKT cells strongly promotes the proliferation of HBsAg-specific CTLs via the production of high levels of IL-2. The enhancement of IL-2 production was observed at least 24 hours after the administration of $\alpha$-GalCer. Although IL-2, IL-4, IFN- $\gamma$, and TNF- $\alpha$ production was found to increase after $\alpha$-GalCer administration, the contribution of IL-2 was significantly higher than that of other cytokines (IL-4, IFN- $\gamma$, and TNF- $\alpha$ ) in the enhancement of CTL production. The blocking of IL-2/IL-2 receptor signal led to an inhibition of IFN- $\gamma$ and IL-12 production by DC and impaired T-cell stimulatory activity [34]. IL-2/IL-2 receptor signal contributes to various cytokines that play an important role in CTL induction. Another report showed that the adjuvant activity of $\alpha$-GalCer is lost in mice lacking the IFN receptor [35]. These data indicate that IFNs are important for mediating the adjuvant effect of $\alpha$-GalCer. IFN- $\gamma$ secreted by NKT and/or NK cells acts on antigenpresenting cells (APCs) by upregulating the MHC class I processing machinery or enhances the acquired APCsmediated immune response by directly acting on antigenspecific CD8-positive T cells. Moreno et al. showed that antiIFN- $\gamma$ antibody inhibits the enhancement of CTL induction by $\alpha$-GalCer [36]. IL-12 production from APCs is also enhanced by NKT cells activation following CD40-CD40 ligand (L) interaction [37, 38]. Type I NKT cells bridge innate and adaptive immune responses by stimulating the production of CTLs in an IFN- $\gamma$ - and/or IL-12-dependent manner [38, 39]. 


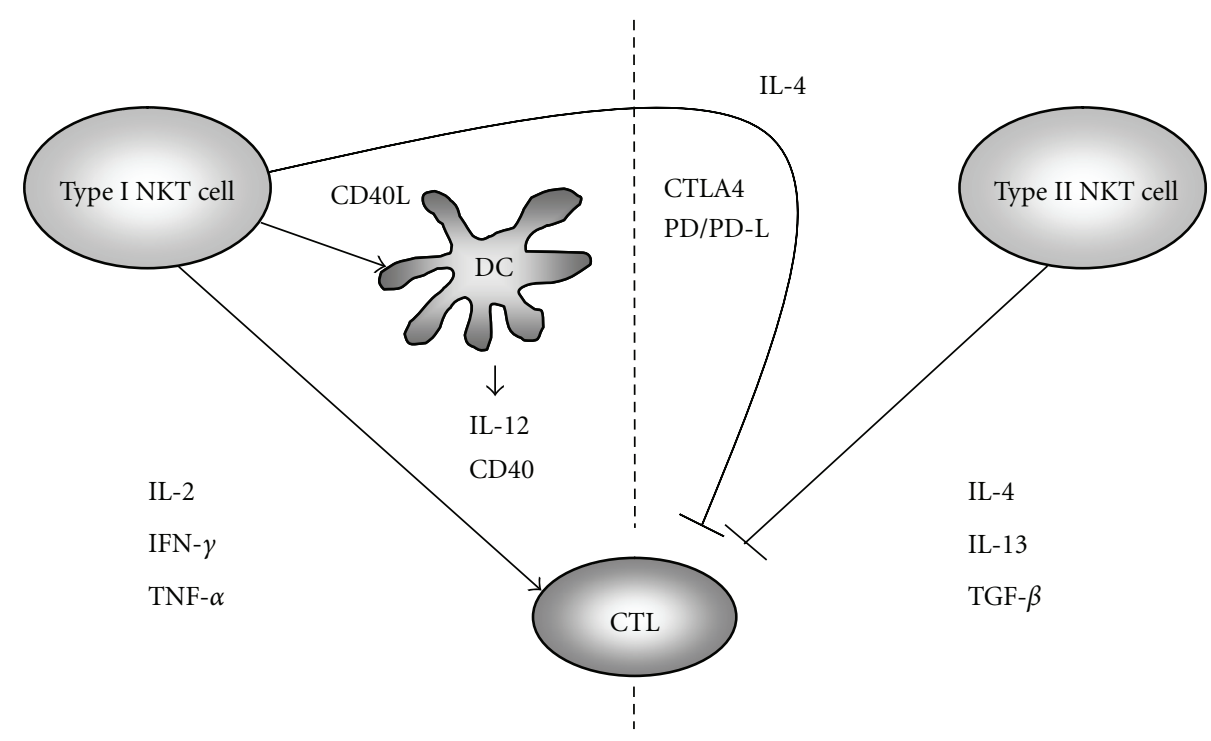

CTLs activation

CTLs suppression

Figure 1: Cellular and molecular mechanisms of CTLs responses mediated by type I and type II NKT cells. Activated type I NKT cells have two distinct effects that regulate CTL function. CTLs are activated by type I NKT cells via cytokines (IL-2, IL-12, IFN- $\gamma$, and TNF- $\alpha$ ) and costimulatory molecules (CD40L and CD28). In contrast, increased expression of Th2 cytokines (IL-4) and other costimulatory molecules (CTLA-4 and PD-L) inhibits CTL production or activation. Activated type II NKT cells suppress CTL activity via cytokines (IL-4, IL-13, and TGF- $\beta$ ).

2.2. Costimulatory Signals Mediate in CTL Induction via NKT Cell Activation. The activation of CD8-positive T cells occurs when naïve cells encounter APCs; this activation depends on (1) the number of MHC complexes that are present on the APCs and the affinity of TCRs for the MHC complexes and (2) the signals provided by the APCs in the form of costimulatory molecules. The B7/CD28 and CD40/CD40L costimulatory pathways are the best studied costimulatory interaction pathways that contribute to $\mathrm{T}$ cell activation and production. NKT cell activation by $\alpha$-GalCer can upregulate costimulatory molecules (CD40, CD80, and CD86) in both CD8+ and CD8- DC subsets [40]. This enhancement of costimulatory regulation is necessary for the adjuvant function of $\alpha$-GalCer in vivo. With regard to the role of costimulatory signals in NKT cell functions, costimulatory molecules including CD28, ICOS, CD40, and $4-1 \mathrm{BB}$ are known to promote Ag-induced activation and cytokine production by NKT cells [41-45]. Hayakawa et al. showed that $\alpha$-GalCer-induced Th1-type responses, represented by enhanced cytotoxic activity of splenic or hepatic mononuclear cells and an antimetastatic effect, were impaired in both CD28-deficient and CD40-deficient mice [41]. In contrast, $\alpha$-GalCer-induced Th2-type responses, represented by increased serum IgE and IgG1 levels, were impaired in the absence of the CD28 costimulatory pathway but not in the absence of the CD40 costimulatory pathway. These data indicated that both CD40/CD40L and CD28/B7 interaction play a critical role in promoting CTL inducted by $\alpha$-GalCer. Thus, these costimulatory molecules contribute to the activation of type I NKT cells and the activation and production of CTLs.
Previous report demonstrated that coadministration of OVA and $\alpha$-GalCer led to a significant increase in OVA257264-specific CD8 T cells over that in animals given OVA and vehicle alone [23]. These results indicated that the levels of cross-presentation were markedly increased by concomitant stimulation of iNKT cell activity. The enhancement of crosspresentation in APC may also increase the antigen specific T cell responses.

MHCs and the process of antigen presentation are currently gaining wide attention in the field of immunology. The immune system contains a distinct group of antigenpresenting cells called DCs, which are specialized for the capture of antigens and induction of T cell immunity. Several mechanistic studies have revealed the importance of DCs in CTL production [46-48]. CD40L and TNF- $\alpha$ are two of the most potent stimuli for DC maturation. Mature DCs express high levels of CD40, whereas activated T cells express CD40L. Therefore, successful T cell-DC interaction should enable prolonged survival of DCs via CD40/CD40L interaction.

$\alpha$-GalCer upregulates CD40L expression on type I NKT cells and mediates the maturation and activation of DCs to produce IL-12 $[37,38]$. IL-12 from DCs activates type I NKT cells to produce IFN- $\gamma$, which in turn stimulates NK cells and CTL-mediated cytotoxicity $[49,50]$. Moreover, $\alpha$ GalCer-activated NKT cells also induce the maturation of DCs, which contributes to the upregulation of Th1 responses $[40,51]$. This upregulation of Th1 responses promotes CTL producton. We previously validated factors that play a critical role in increasing the number of HBV-specific CTLs after in vivo administration of the HBV antigen and $\alpha$-GalCer [22]. 
The CD40-CD40L interaction was found to play a critical role in promoting CTL production via the activation of the type I NKT cells.

\section{Role of NKT Cells in CTL Suppression}

Several reports have indicated that NKT cells also play a suppressive role in the regulation of immunity. Further, this immunosuppressive action of type I and type II NKT cells may also affect CTL production and activation. This section focuses on the effects of several cytokines, such as IL-4, IL-13, and transforming growth factor beta (TGF$\beta$ ), and several costimulatory molecules, such as cytotoxic T lymphocyte associated antigen-(CTLA-4), programmed death (PD)-1, and lymphocyte activation gene-(LAG-3), on the suppression of CTLs production and activation (Figure 1).

3.1. Cytokines Mediate CTL Suppression. IL-4, IL-13, and TGF- $\beta$ are known to suppress immune response and are actively secreted upon NKT cell activation. TGF- $\beta$ has strong inhibitory effects on the immune system and negatively affects many immune cell types and their functions [52, 53]; TGF- $\beta 1$-deficient mice contain spontaneously activated T cells and die from massive inflammation of vital organs [54]. The blocking of TGF- $\beta$ by an anti-TGF- $\beta$ antibody synergistically enhanced tumor vaccine efficacy; this protection was mediated by CD8-positive T cells [55]. Thus, TGF- $\beta$ can suppress immunity via the impairment of CTL function. $\alpha$-GalCer administration into mice is known to induce moderate hepatitis [56]. Zhou et al. recently found that the commercially available $\alpha$-GalCer derivative, $\alpha$-galactosylC18-ceramide ( $\alpha$-Gal-C18-Cer) identical to $\alpha$-GalCer except for 1 double bond in the sphingosine side chain at a location similar to that found in isoglobotrihexosylceramide (iGb3) [57], activates hepatic type I NKT cells (as reflected by IFN- $\gamma$ production) but does not induce biochemical hepatitis, even at intravenous doses of up to $40 \mu \mathrm{g} / \mathrm{mouse}$. In this experimental model, the activation of type I NKT cells by $\alpha$-Gal-C18-Cer results in the recruitment of TGF$\beta$-producing CD4-positive Foxp3+ $\mathrm{T}$ cells in the liver. Another report demonstrated that $\alpha$-Gal-C18-Cer markedly increase hepatic CXCR3 level on the dependentmanner of NKT cells [58]. The increase of CXCR3 expression recruits CXC3-positive regulatory T cells. Thus, $\alpha$-Gal-C18-Cer can potentially suppress CTLs via the recruitment of regulatory T cells.

In a fibrosarcoma model, in which the tumor recurred at the site of tumor challenge following primary tumor growth and spontaneous regression, CTL function against the tumor was impaired by CD4-positive $\mathrm{T}$ cells [59]. These suppressive CD4-positive $\mathrm{T}$ cells were found to be IL-13-producing CD1d-restricted NKT cells [60, 61]. CD1d knockout $(\mathrm{KO})$ mice were highly resistant to the tumor, and IL-13 secretion by $\mathrm{T}$ cells was significantly reduced in these mice model. This was consistent with the finding that CD4-positive NKT cells from tumor-bearing mice upregulate IL-13 production. These results clearly indicated that CD4-positive NKT cells are the main source of IL13 in tumor-bearing mice because CD4-positive $\mathrm{T}$ cells from NKT cell-deficient mice produce very low levels of IL-13. IL-13 secreted by NKT cells is thought to impair CTL activation. IL-13 also induces the production of TGF$\beta$ from myeloid-derived cells, and TGF- $\beta$ suppresses CTLs. Recent studies have reported that these CD4-positive CD1drestricted NKT cells are type II NKT cells [11]. Type II NKT cells have variable TCR gene rearrangements that are distinct from those of type I NKT cells; further, type II NKT cells are activated after sulfatide administration [10]. The activation of type II NKT cells by sulfatide prevents experimental autoimmune encephalomyelitis, and concanavalin A-induced hepatitis $[10,62]$. Sulfatide-mediated protection from autoimmune diseases involves the regulation of type I NKT cells, inhibition of effector functions of conventional T cells, and modification of DC function. CTLs functions are also impaired by the inhibition of conventional $\mathrm{T}$ cells and DC functions. Thus, the activation of type II NKT cells by sulfatide may be useful in the development of novel strategies for the treatment of autoimmune diseases associated with activated CTLs.

Type I NKT cells that can strongly secrete Th2 cytokines also contribute to immunosuppression. Bone marrowderived NKT cells could inhibit graft versus host disease (GVHD) in a mouse model [63]. The same group reported similar results by using a different model of GVHD suppression [64]. In both studies, the inhibition of GVHD depended on the ability of NKT cells to produce IL-4. IL-4 production by NKT cells was found to dominate the response of GVHD suppression and thereby counteract the potential effect of Th1 cytokines on these cells, at least in these models.

Previous report indicated that $\alpha$-GalCer prevents development in nonobese diabetic (NOD) mice [65]. NOD mice have functional V $\alpha 14$ NKT cells that can be stimulated with $\alpha$-GalCer to potentiate Th2 (IL-4, IL-10) immune responses. Furthermore, Beaudoin et al. demonstrated that type I NKT cells can inhibit the differentiation of naïve $\mathrm{T}$ cells into Th1 effectors, and this inhibition was strong enough to block the development of diabetes [66]. Activation of type I NKT cells might be useful for therapeutic intervention in human diseases characterized by Th1-mediated pathology such as Type 1 diabetes.

3.2. Costimulatory Signals Mediate CTL Suppression. T cell activation is induced on B7CD28 or CD40/CD40L interactions to provide costimulatory signals. Recent reports have revealed that several additional molecules on the APCs provide costimulatory signals. These signaling molecules can be either positive effectors or inhibitory molecules, and the paradigm shift from $\mathrm{T}$ cell activation to tolerance depends on the integration of the myriad interactions between various cell surface molecules and their effects on cell fate decisions. Several of these proteins, such as CTLA-4, PD-1, and LAG-3, and their effect on the induction of $\mathrm{T}$ cell tolerance in CTLs need to be studied.

CTLA-4 is a member of the CD28 receptor family, and is an inhibitory molecule that suppresses $\mathrm{T}$ cell activation [67]. CTLA-4, like CD28, binds to B7 molecules, but with 
an affinity that is $20-50$-fold higher than that of CD28 [68]. The surface expression of CTLA-4 is upregulated in activated $\mathrm{T}$ cells, presumably as part of a normal negative feedback loop to terminate activation. Inhibition of CTLA4 activity by using blocking antibodies against CTLA4 prevents anergy in CD4-positive $\mathrm{T}$ cells in several in vivo models; this implies that CTLA-4 is an important molecule involved in anergy induction. However, CTLA4 is probably not required for anergy induction in CD8positive $\mathrm{T}$ cells, because $2 \mathrm{C} \mathrm{T}$ cells from CTLA- $4 \mathrm{KO}$ mice are equally susceptible to anergy as $\mathrm{T}$ cells from their wildtype littermates. Further, tolerance against tissue antigens expressed on cells that lack B7 molecules could explain the CTLA-4-independent CD8-positive T cells tolerance. Thus, these results emphasize the potential mechanistic differences in the induction of tolerance between CD4-positive and CD8-positive T cells. The contribution of type I NKT cells was recently investigated in a murine model of cancer treated with radiotherapy and CTLA-4 blockade [69]. Compared with wild-type mice, type I NKT cells KO mice showed markedly high survival and cure rates following radiotherapy and [69] CTLA-4 blockade; this suggests that type I NKT cells can play an important role in regulating the response to treatment.

PD-1 is another important inhibitory receptor that has been implicated in T cell tolerance and autoimmunity [70]. $\mathrm{PD}-1$ is an inducible receptor found on $\mathrm{T}$ cells and has been shown to downregulate $\mathrm{T}$ cell activation and the development of effector functions. The ligands that bind to PD-1, namely, PD-L1 and PD-L2, were identified on the basis of sequence similarity to common B7 molecules. PD-L1 is widely expressed on cells of hematopoietic and parenchymal origin, whereas PD-L2 expression is more tightly regulated, and is observed on macrophages and DCs [71]. Several studies have validated that PD-1/PD-L1 interaction is crucial for the development of tolerance in CD8-positive T cells. Furthermore, PD-1 depletion leads to an increase in the absolute number of CD8-positive $\mathrm{T}$ cells, thereby indicating that PD-1 mediates tolerance by downregulating the proliferation of $\mathrm{T}$ cells. $\mathrm{T}$ cells primed in the absence of PD-1/PD-L1 interaction also actively secrete cytokines and produce granzymes [72]. These results indicate that PD-1 generates tolerance to autoreactive $\mathrm{T}$ cells by downregulating CD8-positive $\mathrm{T}$ cell proliferation and differentiation. The blocking of PD-1/PD-L interactions during $\alpha$-GalCer treatment prevents the induction of type I NKT cell anergy, thereby preserving the therapeutic activity of these cells against B16 tumors [73]. Type I NKT cells in $\alpha$-GalCer-treated PD-1-deficient mice were also found to retain their antimetastatic activity. Previously, it was reported that a single administration of $\alpha$-GalCer induces long-term NKT cell unresponsiveness in mice. NKT cells failed to proliferate and produce IFN- $\gamma$ upon $\alpha$-GalCer restimulation [74]. Therefore, $\alpha$-GalCer that induced the conventional $\mathrm{T}$ cell activation also disappear by this NKT cell anergy. Recent study reveals that the PD-1/PD-L1 interaction is essential for the induction and maintenance of iNKT cell anergy [75]. The blocking of PD-1/PD-L1 interaction may enhance the induction of antigen-specific CTL response by
$\alpha$-GalCer stimulation. Akbari et al. investigated the role of PD-L1 and PD-L2 in regulating type I NKT cells-cellmediated airway hyperreactivity (AHR) in a murine model of asthma [76]. AHR severity and airway inflammation were significantly greater in PD-L2 KO mice than in wildtype mice after both ovalbumin sensitization and challenge or $\alpha$-GalCer administration. Type I NKT cells obtained from PD-L2 KO mice produced significantly more IL4 than those obtained from control mice. These results suggest that PD-1 or PD-2/PD-L interaction is important to induce anergy in activated type I NKT cells. This anergy may result in the impairment of CTL production and activation.

\section{Conclusion}

The concept of immune modulation is based on the idea that the host immune system plays a critical role in promoting host protection against pathogens or cancer. In particular, CTLs play a central role in the exclusion of intracellular pathogens or cancer cells, and the modulation of CTL production or activation is beneficial for controlling the disease. NKT cells have two opposite functions: immunoactive and immunosuppressive functions. Type I and type II NKT cells exhibit these immunoregulatory functions, and a control of this bipolar NKT cell functions is necessary for effective immunotherapy against chronic viral infection, cancer, and autoimmune diseases.

\section{References}

[1] Y. Yang, Z. Xiang, H. C. J. Ertl, and J. M. Wilson, "Upregulation of class I major histocompatibility complex antigens by interferon $\gamma$ is necessary for T-cell-mediated elimination of recombinant adenovirus-infected hepatocytes in vivo," Proceedings of the National Academy of Sciences of the United States of America, vol. 92, no. 16, pp. 7257-7261, 1995.

[2] X. Y. Mo, R. A. Tripp, M. Y. Sangster, and P. C. Doherty, "The cytotoxic T-lymphocyte response to sendai virus is unimpaired in the absence of gamma interferon," Journal of Virology, vol. 71, no. 3, pp. 1906-1910, 1997.

[3] T. Kawano, J. Cui, Y. Koezuka, et al., "CD1d-restricted and TCR-mediated activation of V $\alpha 14$ NKT cells by glycosylceramides," Science, vol. 278, no. 5343, pp. 1626-1629, 1997.

[4] M. Taniguchi, K. I. Seino, and T. Nakayama, "The NKT cell system: bridging innate and acquired immunity," Nature Immunology, vol. 4, no. 12, pp. 1164-1165, 2003.

[5] T. Kawano, J. Cui, Y. Koezuka, et al., "Natural killer-like nonspecific tumor cell lysis mediated by specific ligand-activated V $\alpha 14$ NKT cells," Proceedings of the National Academy of Sciences of the United States of America, vol. 95, no. 10, pp. 5690-5693, 1998.

[6] M. Nieda, A. Nicol, Y. Koezuka, et al., "TRAIL expression by activated human CD4+V $\alpha 24 \mathrm{NKT}$ cells induces in vitro and in vivo apoptosis of human acute myeloid leukemia cells," Blood, vol. 97, no. 7, pp. 2067-2074, 2001.

[7] J. L. Baron, L. Gardiner, S. Nishimura, K. Shinkai, R. Locksley, and D. Ganem, "Activation of a nonclassical NKT cell subset in a transgenic mouse model of hepatitis B virus infection," Immunity, vol. 16, no. 4, pp. 583-594, 2002. 
[8] M. A. Exley, Q. He, O. Cheng, et al., "Cutting edge: compartmentalization of Th1-like noninvariant CD1d-reactive T cells in hepatitis C virus-infected liver," Journal of Immunology, vol. 168, no. 4, pp. 1519-1523, 2002.

[9] I. J. Fuss, F. Heller, M. Boirivant, et al., "Nonclassical CD1drestricted NK T cells that produce IL-13 characterize an atypical Th2 response in ulcerative colitis," Journal of Clinical Investigation, vol. 113, no. 10, pp. 1490-1497, 2004.

[10] A. Jahng, I. Maricic, C. Aguilera, S. Cardell, R. C. Halder, and V. Kumar, "Prevention of autoimmunity by targeting a distinct, noninvariant CD1d-reactive $\mathrm{T}$ cell population reactive to sulfatide," Journal of Experimental Medicine, vol. 199, no. 7, pp. 947-957, 2004.

[11] M. Terabe, J. Swann, E. Ambrosino, et al., "A nonclassical nonV $\alpha 14 \mathrm{~J} \alpha 18$ CD1d-restricted (type II) NKT cell is sufficient for down-regulation of tumor immunosurveillance," Journal of Experimental Medicine, vol. 202, no. 12, pp. 1627-1633, 2005.

[12] E. Ambrosino, M. Terabe, R. C. Halder, et al., "Crossregulation between type I and type II NKT cells in regulating tumor immunity: a new immunoregulatory axis," Journal of Immunology, vol. 179, no. 8, pp. 5126-5136, 2007.

[13] T. Takahashi, M. Nieda, Y. Koezuka, et al., "Analysis of human $\mathrm{V} \alpha 24^{+} \mathrm{CD}^{+}$NKT cells activated by $\alpha$ - glycosylceramidepulsed monocyte-derived dendritic cells," Journal of Immunology, vol. 164, no. 9, pp. 4458-4464, 2000.

[14] L. S. Metelitsa, O. V. Naidenko, A. Kant, et al., "Human NKT cells mediate antitumor cytotoxicity directly by recognizing target cell CD1d with bound ligand or indirectly by producing IL-2 to activate NK cells," Journal of Immunology, vol. 167, no. 6, pp. 3114-3122, 2001.

[15] J. Cui, T. Shin, T. Kawano, et al., "Requirement for V $\alpha 14$ NKT cells in IL-12-mediated rejection of tumors," Science, vol. 278, no. 5343, pp. 1623-1626, 1997.

[16] M. A. Exley, N. J. Bigley, O. Cheng, et al., "CD1d-reactive Tcell activation leads to amelioration of disease caused by diabetogenic encephalomyocarditis virus," Journal of Leukocyte Biology, vol. 69, no. 5, pp. 713-718, 2001.

[17] S. L. H. van Dommelen, H. A. Tabarias, M. J. Smyth, and M. A. Degli-Esposti, "Activation of natural killer (NK) T cells during murine cytomegalovirus infection enhances the antiviral response mediated by NK cells," Journal of Virology, vol. 77, no. 3, pp. 1877-1884, 2003.

[18] T. R. Johnson, S. Hong, L. Van Kaer, Y. Koezuka, and B. S. Graham, "NK T cells contribute to expansion of $\mathrm{CD}^{+}$ $\mathrm{T}$ cells and amplification of antiviral immune responses to respiratory syncytial virus," Journal of Virology, vol. 76, no. 9, pp. 4294-4303, 2002.

[19] H. Ito, K. Ando, T. Nakayama, et al., "Role of V $\alpha 14$ NKT cells in the development of impaired liver regeneration in vivo," Hepatology, vol. 38, no. 5, pp. 1116-1124, 2003.

[20] H. Ohtaki, H. Ito, K. Ando, et al., "V $\alpha 14$ NKT cells activated by alpha-galactosylceramide augment lipopolysaccharideinduced nitric oxide production in mouse intra-hepatic lymphocytes," Biochemical and Biophysical Research Communications, vol. 378, no. 3, pp. 579-583, 2009.

[21] T. Shin, T. Nakayama, Y. Akutsu, et al., "Inhibition of tumor metastasis by adoptive transfer of IL-12-activated V $\alpha 14$ NKT cells," International Journal of Cancer, vol. 91, no. 4, pp. 523$528,2001$.

[22] H. Ito, K. Ando, T. Ishikawa, et al., "Role of $\mathrm{V} \alpha 14^{+}$NKT cells in the development of Hepatitis B virus-specific CTL: activation of $\mathrm{V} \alpha 14^{+}$NKT cells promotes the breakage of CTL tolerance," International Immunology, vol. 20, no. 7, pp. 869-879, 2008.
[23] I. F. Hermans, J. D. Silk, U. Gileadi, et al., "NKT cells enhance $\mathrm{CD}^{+}$and $\mathrm{CD}^{+} \mathrm{T}$ cell responses to soluble antigen in vivo through direct interaction with dendritic cells," Journal of Immunology, vol. 171, no. 10, pp. 5140-5147, 2003.

[24] B. Frankenberger, H. Pohla, E. Noessner, et al., "Influence of CD80, interleukin-2, and interleukin-7 expression in human renal cell carcinoma on the expansion, function, and survival of tumor-specific CTLs," Clinical Cancer Research, vol. 11, no. 5, pp. 1733-1742, 2005.

[25] S.-I. Hiraoka, N. Takeuchi, Y. Bian, et al., "B7.2-Ig fusion proteins enhance IL-4-dependent differentiation of tumorsensitized CD8 ${ }^{+}$cytotoxic T lymphocyte precursors," International Immunology, vol. 17, no. 8, pp. 1071-1079, 2005.

[26] M. Bertagnolli and S. Herrmann, "IL-7 supports the generation of cytotoxic T lymphocytes from thymocytes: multiple lymphokines required for proliferation and cytotoxicity," Journal of Immunology, vol. 145, no. 6, pp. 1706-1712, 1990.

[27] W.-F. Chen and A. Zlotnik, "IL-10: a novel cytotoxic T cell differentiation factor," Journal of Immunology, vol. 147, no. 2, pp. 528-534, 1991.

[28] C. Pardoux, C. Asselin-Paturel, J. Chehimi, F. Gay, F. MamiChouaib, and S. Chouaib, "Functional interaction between TGF- $\beta$ and IL-12 in human primary allogeneic cytotoxicity and proliferative response," Journal of Immunology, vol. 158, no. 1, pp. 136-143, 1997.

[29] T. Kanai, E. K. Thomas, Y. Yasutomi, and N. L. Letvin, "IL-15 stimulates the expansion of AIDS virus-specific CTL," Journal of Immunology, vol. 157, no. 8, pp. 3681-3687, 1996.

[30] S. Kasahara, K. Ando, K. Saito, et al., "Lack of tumor necrosis factor alpha induces impaired proliferation of hepatitis B virus-specific cytotoxic T lymphocytes," Journal of Virology, vol. 77, no. 4, pp. 2469-2476, 2003.

[31] M. K. Gately, R. R. Warrier, S. Honasoge, et al., "Administration of recombinant IL-12 to normal mice enhances cytolytic lymphocyte activity and induces production of IFN- $\gamma$ in vivo," International Immunology, vol. 6, no. 1, pp. 157-167, 1994.

[32] T. P. Leist, M. Kohler, M. Eppler, and R. M. Zinkernagel, "Effects of treatment with IL-2 receptor specific monoclonal antibody in mice. Inhibition of cytotoxic T cell responses but not of T help," Journal of Immunology, vol. 143, no. 2, pp. 628632, 1989.

[33] C.-T. Lin, Y.-C. Tsai, L. He, et al., "DNA vaccines encoding IL2 linked to HPV-16 E7 antigen generate enhanced E7-specific CTL responses and antitumor activity," Immunology Letters, vol. 114, no. 2, pp. 86-93, 2007.

[34] T. Fukao and S. Koyasu, "Expression of functional IL-2 receptors on mature splenic dendritic cells," European Journal of Immunology, vol. 30, no. 5, pp. 1453-1457, 2000.

[35] G. Gonzalez-Aseguinolaza, L. Van Kaer, C. C. Bergmann, et al., "Natural killer T cell ligand $\alpha$-galactosylceramide enhances protective immunity induced by malaria vaccines," Journal of Experimental Medicine, vol. 195, no. 5, pp. 617-624, 2002.

[36] M. Moreno, J. W. Molling, S. von Mensdorff-Pouilly, et al., "IFN-gamma-producing human invariant NKT cells promote tumor-associated antigen-specific cytotoxic T cell responses," The Journal of Immunology, vol. 181, pp. 2446-2454, 2008.

[37] M. Tomura, W.-G. Yu, H.-J. Ahn, et al., "A novel function of $\mathrm{V} \alpha 14^{+} \mathrm{CD} 4^{+} \mathrm{NKT}$ cells: stimulation of IL-12 production by antigen-presenting cells in the innate immune system," Journal of Immunology, vol. 163, no. 1, pp. 93-101, 1999.

[38] H. Kitamura, K. Iwakabe, T. Yahata, et al., "The natural killer $\mathrm{T}(\mathrm{NKT})$ cell ligand $\alpha$-galactosylceramide demonstrates its immunopotentiating effect by inducing interleukin (IL)-12 production by dendritic cells and IL- 12 receptor expression on 
NKT cells," Journal of Experimental Medicine, vol. 189, no. 7, pp. 1121-1128, 1999.

[39] G. Eberl, P. Brawand, and H. R. MacDonald, "Selective bystander proliferation of memory $\mathrm{CD}^{+}$and $\mathrm{CD}^{+} \mathrm{T}$ cells upon NK T or T cell activation," Journal of Immunology, vol. 165, no. 8, pp. 4305-4311, 2000.

[40] S.-I. Fujii, K. Shimizu, C. Smith, L. Bonifaz, and R. M. Steinman, "Activation of natural killer T cells by $\alpha$ galactosylceramide rapidly induces the full maturation of dendritic cells in vivo and thereby acts as an adjuvant for combined CD4 and CD8 T cell immunity to a coadministered protein," Journal of Experimental Medicine, vol. 198, no. 2, pp. 267-279, 2003.

[41] Y. Hayakawa, K. Takeda, H. Yagita, L. Van Kaer, I. Saiki, and K. Okumura, "Differential regulation of Th1 and Th2 functions of NKT cells by CD28 and CD40 costimulatory pathways," Journal of Immunology, vol. 166, no. 10, pp. 6012-6018, 2001.

[42] D. S. Vinay, B. K. Choi, J. S. Bae, W. Y. Kim, B. M. Gebhardt, and B. S. Kwon, "CD137-deficient mice have reduced NK/NKT cell numbers and function, are resistant to lipopolysaccharide-induced shock syndromes, and have lower IL-4 responses," Journal of Immunology, vol. 173, no. 6, pp. 4218-4229, 2004.

[43] H. Kaneda, K. Takeda, T. Ota, et al., "ICOS costimulates invariant NKT cell activation," Biochemical and Biophysical Research Communications, vol. 327, no. 1, pp. 201-207, 2005.

[44] A. Marschner, S. Rothenfusser, V. Hornung, et al., "CpG ODN enhance antigen-specific NKT cell activation via plasmacytoid dendritic cells," European Journal of Immunology, vol. 35, no. 8, pp. 2347-2357, 2005.

[45] A. P. Uldrich, N. Y. Crowe, K. Kyparissoudis, et al., "NKT cell stimulation with glycolipid antigen in vivo: costimulation-dependent expansion, bim-dependent contraction, and hyporesponsiveness to further antigenic challenge," Journal of Immunology, vol. 175, no. 5, pp. 3092-3101, 2005.

[46] S. Freigang, H. C. Probst, and M. van den Broek, "DC infection promotes antiviral CTL priming: the 'Winkelried' strategy," Trends in Immunology, vol. 26, no. 1, pp. 13-18, 2005.

[47] H. Ikeda, K. Chamoto, T. Tsuji, et al., "The critical role of type1 innate and acquired immunity in tumor immunotherapy," Cancer Science, vol. 95, no. 9, pp. 697-703, 2004.

[48] B. Ludewig, B. Odermatt, A. F. Ochsenbein, R. M. Zinkernagel, and H. Hengartner, "Role of dendritic cells in the induction and maintenance of autoimmune diseases," Immunological Reviews, vol. 169, pp. 45-54, 1999.

[49] M. J. Smyth, N. Y. Crowe, D. G. Pellicci, et al., "Sequential production of interferon-gamma by $\mathrm{NK}_{1.1}{ }^{+} \mathrm{T}$ cells and natural killer cells is essential for the antimetastatic effect of alpha-galactosylceramide," Blood, vol. 99, no. 4, pp. 12591266, 2002.

[50] Y. Hayakawa, K. Takeda, H. Yagita, et al., "Critical contribution of IFN- $\gamma$ and NK cells, but not perforin-mediated cytotoxicity, to anti-metastatic effect of $\alpha$-galactosylceramide," European Journal of Immunology, vol. 31, no. 6, pp. 1720-1727, 2001.

[51] S.-I. Fujii, K. Liu, C. Smith, A. J. Bonito, and R. M. Steinman, "The linkage of innate to adaptive immunity via maturing dendritic cells in vivo requires CD40 ligation in addition to antigen presentation and CD80/86 costimulation," Journal of Experimental Medicine, vol. 199, no. 12, pp. 1607-1618, 2004.

[52] L. Gorelik and R. A. Flavell, "Transforming growth factor- $\beta$ in T-cell biology," Nature Reviews Immunology, vol. 2, no. 1, pp. 46-53, 2002.

[53] J. J. Letterio, "Murine models define the role of TGF- $\beta$ as a master regulator of immune cell function," Cytokine and Growth Factor Reviews, vol. 11, no. 1-2, pp. 81-87, 2000.

[54] R. J. Diebold, M. J. Eis, M. Yin, et al., "Early-onset multifocal inflammation in the transforming growth factor $\beta 1$-null mouse is lymphocyte mediated," Proceedings of the National Academy of Sciences of the United States of America, vol. 92, no. 26, pp. 12215-12219, 1995.

[55] S. Takaku, M. Terabe, E. Ambrosino, et al., "Blockade of TGF$\beta$ enhances tumor vaccine efficacy mediated by CD8 ${ }^{+}$T cells," International Journal of Cancer, vol. 126, no. 7, pp. 1666-1674, 2010.

[56] M. Biburger and G. Tiegs, “ $\alpha$-galactosylceramide-induced liver injury in mice is mediated by TNF- $\alpha$ but independent of Kupffer cells," Journal of Immunology, vol. 175, no. 3, pp. 1540-1550, 2005.

[57] D. Zhou, J. Mattner, C. Cantu III, et al., "Lysosomal glycosphingolipid recognition by NKT cells," Science, vol. 306, no. 5702, pp. 1786-1789, 2004.

[58] T. Santodomingo-Garzon, J. Han, T. Le, Y. Yang, and M. G. Swain, "Natural killer $\mathrm{T}$ cells regulate the homing of chemokine CXC receptor 3-positive regulatory $\mathrm{T}$ cells to the liver in mice," Hepatology, vol. 49, no. 4, pp. 1267-1276, 2009.

[59] S. Matsui, J. D. Ahlers, A. O. Vortmeyer, et al., "A model for $\mathrm{CD}^{+} \mathrm{CTL}$ tumor immunosurveillance and regulation of tumor escape by CD4 T cells through an effect on quality of CTL," Journal of Immunology, vol. 163, no. 1, pp. 184-193, 1999.

[60] M. Terabe, S. Matsui, N. Noben-Trauth, et al., "NKT cellmediated repression of tumor immunosurveillance by IL-13 and the IL-4R-STAT6 pathway," Nature Immunology, vol. 1, no. 6, pp. 515-520, 2000.

[61] M. Terabe, S. Matsui, J.-M. Park, et al., “Transforming growth factor- $\beta$ production and myeloid cells are an effector mechanism through which CD1d-restricted T cells block cytotoxic $\mathrm{T}$ lymphocyte-mediated tumor immunosurveillance: abrogation prevents tumor recurrence," Journal of Experimental Medicine, vol. 198, no. 11, pp. 1741-1752, 2003.

[62] R. C. Halder, C. Aguilera, I. Maricic, and V. Kumar, "Type II NKT cell-mediated anergy induction in type I NKT cells prevents inflammatory liver disease," Journal of Clinical Investigation, vol. 117, no. 8, pp. 2302-2312, 2007.

[63] D. Zeng, D. Lewis, S. Dejbakhsh-Jones, et al., "Bone marrow $\mathrm{NK} 1.1^{-}$and NK1.1 $1^{+} \mathrm{T}$ cells reciprocally regulate acute graft versus host disease," Journal of Experimental Medicine, vol. 189, no. 7, pp. 1073-1081, 1999.

[64] F. Lan, D. Zeng, M. Higuchi, et al., "Predominance of NK1. $1^{+} \mathrm{TCR} \alpha \beta^{+}$or $\mathrm{DX} 5^{+} \mathrm{TCR} \alpha \beta^{+} \mathrm{T}$ cells in mice conditioned with fractionated lymphoid irradiation protects against graftversus, host disease: "Natural suppressor" cells," Journal of Immunology, vol. 167, no. 4, pp. 2087-2096, 2001.

[65] S. Hong, M. T. Wilson, I. Serizawa, et al., "The natural killer T-cell ligand $\alpha$-galactosylceramide prevents autoimmune diabetes in non-obese diabetic mice," Nature Medicine, vol. 7, no. 9, pp. 1052-1056, 2001.

[66] L. Beaudoin, V. E. Laloux, J. Novak, B. Lucas, and A. Lehuen, "NKT cells inhibit the onset of diabetes by impairing the development of pathogenic $\mathrm{T}$ cells specific for pancreatic $\beta$ cells," Immunity, vol. 17, no. 6, pp. 725-736, 2002.

[67] M. L. Alegre, K. A. Frauwirth, and C. B. Thompson, "T-cell regulation by CD28 and CTLA-4," Nature Reviews Immunology, vol. 1, no. 3, pp. 220-228, 2001.

[68] T. L. Walunas, D. J. Lenschow, C. Y. Bakker, et al., "CTLA-4 can function as a negative regulator of $\mathrm{T}$ cell activation," Immunity, vol. 1, no. 5, pp. 405-413, 1994. 
[69] K. A. Pilones, N. Kawashima, A. M. Yang, J. S. Babb, S. C. Formenti, and S. Demaria, "Invariant natural killer T cells regulate breast cancer response to radiation and CTLA-4 blockade," Clinical Cancer Research, vol. 15, no. 2, pp. 597606, 2009.

[70] M. E. Keir, L. M. Francisco, and A. H. Sharpe, "PD-1 and its ligands in T-cell immunity," Current Opinion in Immunology, vol. 19, no. 3, pp. 309-314, 2007.

[71] T. Okazaki and T. Honjo, "The PD-1-PD-L pathway in immunological tolerance," Trends in Immunology, vol. 27, no. 4, pp. 195-201, 2006.

[72] N. Martin-Orozco, Y.-H. Wang, H. Yagita, and C. Dong, "Cutting edge: programed death (PD) ligand-1/PD-1 interaction is required for $\mathrm{CD} 8^{+} \mathrm{T}$ cell tolerance to tissue antigens," Journal of Immunology, vol. 177, no. 12, pp. 8291-8295, 2006.

[73] V. V. Parekh, S. Lalani, S. Kim, et al., "PD-1/PD-L blockade prevents anergy induction and enhances the anti-tumor activities of glycolipid-activated invariant NKT cells," Journal of Immunology, vol. 182, no. 5, pp. 2816-2826, 2009.

[74] V. V. Parekh, M. T. Wilson, D. Olivares-Villagomez, et al., "Glycolipid antigen induces long-term natural killer $\mathrm{T}$ cell anergy in mice," Journal of Clinical Investigation, vol. 115, no. 9, pp. 2572-2583, 2005.

[75] W.-S. Chang, J.-Y. Kim, Y.-J. Kim, et al., "Cutting edge: programmed death-1/programmed death ligand 1 interaction regulates the induction and maintenance of invariant NKT cell anergy," Journal of Immunology, vol. 181, no. 10, pp. 67076710, 2008.

[76] O. Akbari, P. Stock, A. K. Singh, et al., "PD-L1 and PDL2 modulate airway inflammation and iNKT-cell-dependent airway hyperreactivity in opposing directions," Mucosal Immunology, vol. 3, no. 1, pp. 81-91, 2010. 


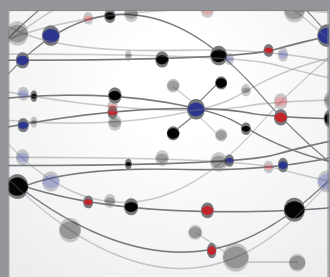

The Scientific World Journal
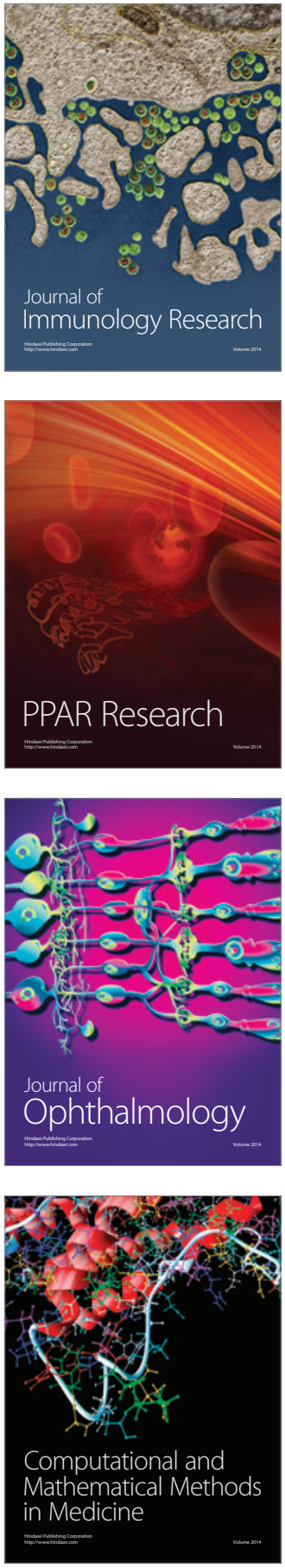

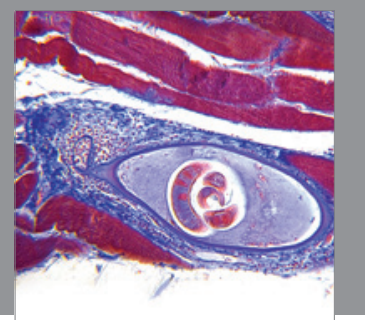

Gastroenterology

Research and Practice
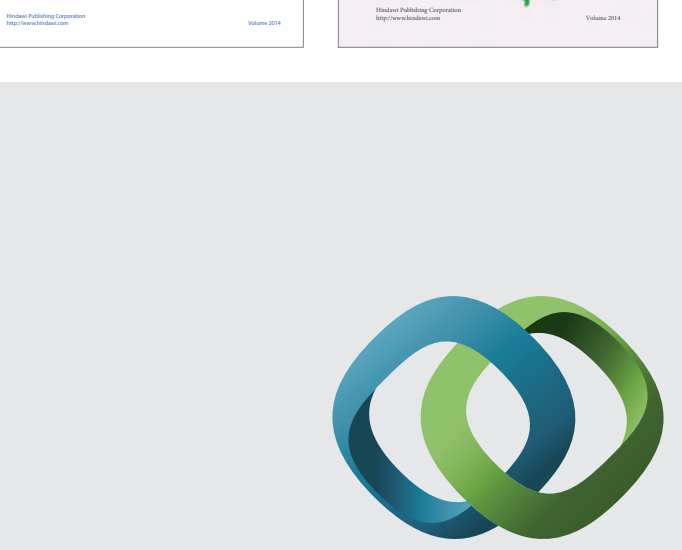

\section{Hindawi}

Submit your manuscripts at

http://www.hindawi.com
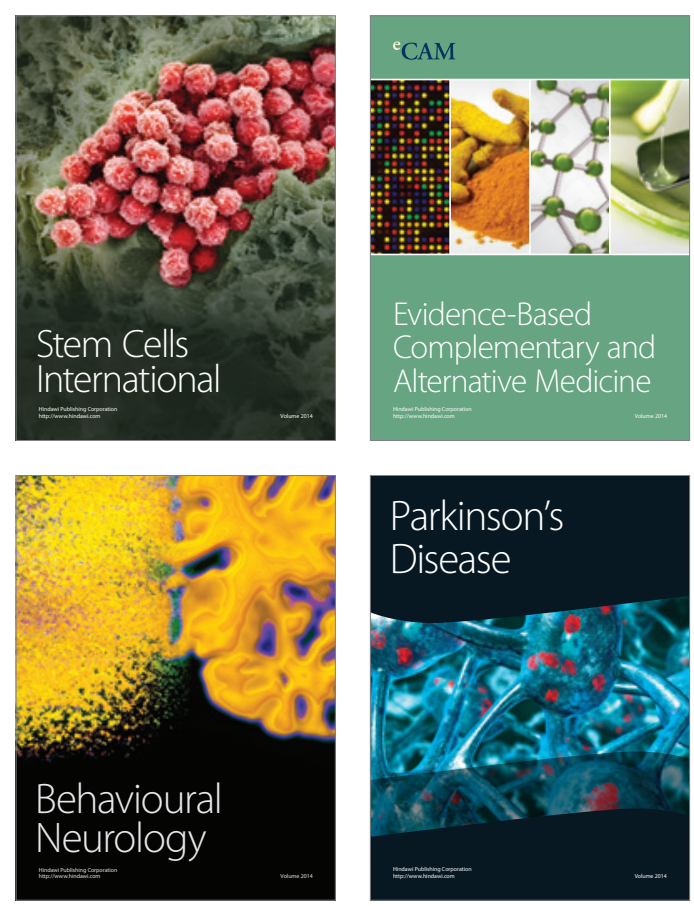

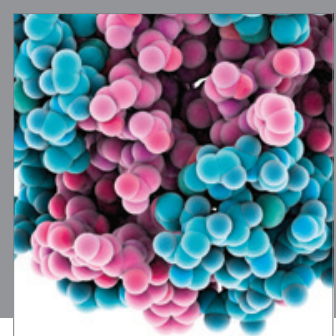

Journal of
Diabetes Research

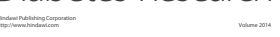

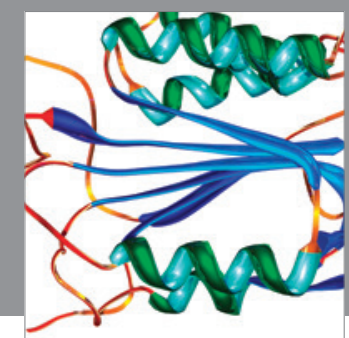

Disease Markers
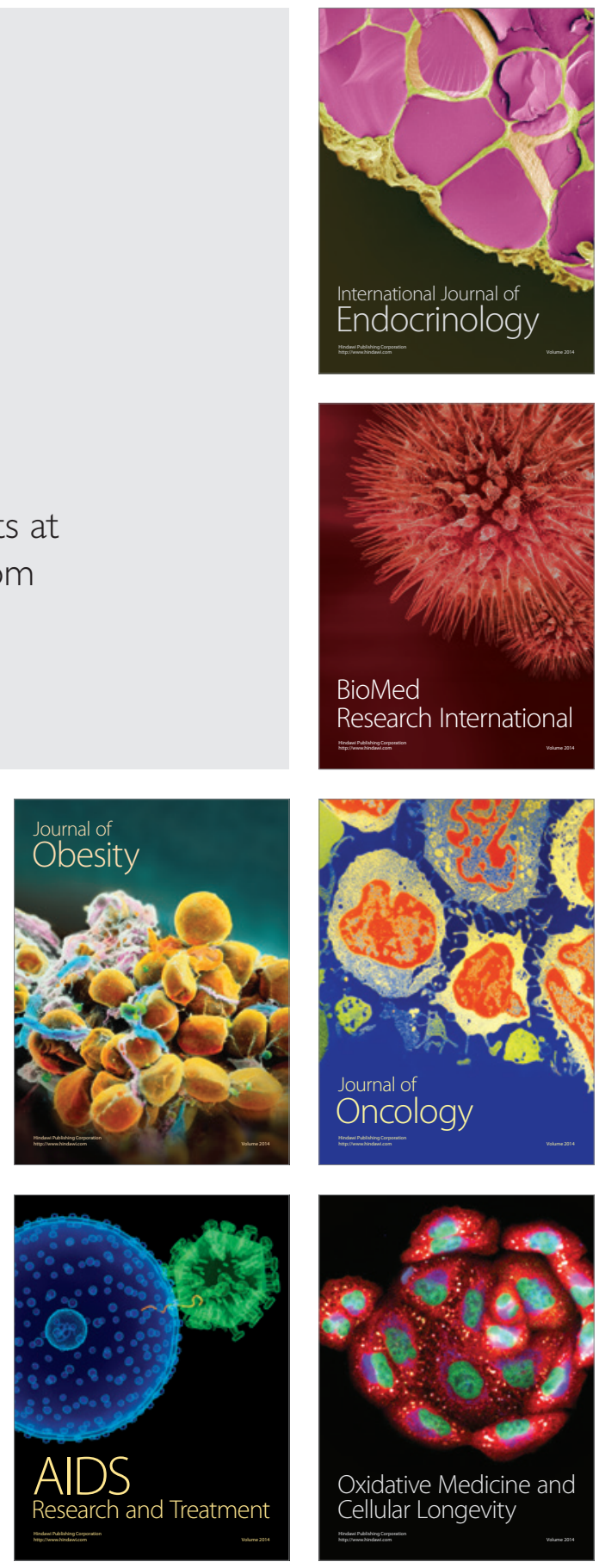